\title{
Do Indigenous American Peoples' Stories Inform the Study of Dog Domestication?
}

\author{
L. David Mech ${ }^{1 *}$ \\ ${ }^{1}$ U.S. Geological Survey, Northern Prairie Wildlife Research Center, Jamestown, USA. ${ }^{2}$ U.S. Geological Survey, The Raptor \\ Center, University of Minnesota, St. Paul, USA. \\ *mechx002@umn.edu
}

\begin{abstract}
I discuss the article "Relationships Between Indigenous American Peoples and Wolves 1: Wolves as Teachers and Guides" (Fogg et al. 2015) and the book "The First Domestication: How Wolves and Humans Coevolved" (Pierotti and Fogg 2017). The article proposed that published stories about interactions between indigenous American peoples and wolves (Canis lupus) provide insight into wolf-human relationships as humans began domesticating wolves. In the book, the authors offer a theory of how wolves and humans coevolved by building on the information in the article and the authors' long experience with captive and pet wolves, wolf-dog hybrids, and dogs. I (1) present arguments and evidence that question the value of indigenous American stories for drawing conclusions about the relationship between early humans and wolves 14,000 yrs BP; (2) demonstrate how indigenous American stories contradict documented information about wolf biology, behavior, and known interactions with humans; and (3) point out important information not considered by the authors about wolf attacks on humans and the importance of rabies in the wolf-human relationship.
\end{abstract}

Received December 18, 2018

OPEN ठACCESS

Accepted April 9, 2019

Published September 2, 2019

DOI 10.14237/ebl.10.1.2019.1474

Keywords American Indians, Canis lupus, Dog domestication, Indigenous peoples, Myths, Wolves

Copyright (C) 2019 by the author(s); licensee Society of Ethnobiology. This is an open-access article distributed under the terms of the Creative Commons Attribution-NonCommercial 4.0 International Public License (https://creativecommons.org/licenses/by-nc/4.0), which permits non-commercial use, distribution, and reproduction in any medium, provided the original author and source are credited.

\section{Introduction}

Details about many aspects of dog domestication from wolves (Canis lupus) are regularly debated, and the application of molecular genetic methodology has recently fostered these debates (Janssens et al. 2018). Information about dog domestication is important to studies of human history because the dog was the first domesticated animal. Determining when, where, and how dog domestication began provides valuable insight into the evolution of human culture.

An important gap in the question of how dogs were domesticated from wolves focuses on the nature of the relationship between early humans and wolves. Although much is known about the nature of current relationships (Fritts et al. 2003), little is known about such relationships 14,500 yrs BP (Pierotti 2012), when the earliest dogs are known (Janssens et al. 2018, 2019). Thus, any information that might shed more light on the subject would be valuable. Fogg et al. (2015) and Pierotti and Fogg (2017) attempted to add such information by examining the relationships between indigenous American peoples and wolves.

These authors synthesized published stories and historical accounts about the interactions between indigenous American peoples and wolves. The authors believed that these stories "...provide insights into the process of domestication of wolves, and such stories may indicate at what stage different peoples were in their relationship with wolves" (Fogg et al. 2015:262). In addition, Pierotti and Fogg (2017) and Fogg et al. (2015:263) argue that indigenous peoples continued to interact similarly with wolves until recent times and that these people's stories from the last few centuries might inform our investigations about ecology and evolution of "culturally important species." Dog domestication did not take place in North America, however, so whatever these North American stories actually portrayed would not necessarily have applied to the Eurasian cultures within which dogs were domesticated (Shannon et al. 
2015; Thalmann et al. 2013; Vonholdt et al. 2010; Wang et al. 2013).

The stories and accounts that Fogg et al. (2015) and Pierotti and Fogg (2017) included all feature regular, positive interactions between indigenous people and wolves, with the wolves teaching the humans how to hunt, caring for injured humans, feeding them, etc. (see below). Based on the assumptions that such positivity between wolves and early humans existed, and relying considerably on non -peer-reviewed literature (Haber and Hollerman 2013; Jans 2015 Marshall 1995; Smith 1978), Pierotti and Fogg (2017) proposed details of how dogs were domesticated. If these offerings are to truly inform us, it is important to determine the degree to which both the Fogg et al. (2015) stories and historical accounts, and other information presented by Pierotti and Fogg (2017) evince the view that some 14,000 yrs BP wolves and humans had a similar type of positive relationship. The objective of this article is to critically examine the stories and accounts of Fogg et al. (2015) and the other information presented by Pierotti and Fogg (2017) in view of what has been documented about wolf ecology, behavior, and interactions with humans.

\section{Wolf Interactions with Humans}

The wolf regularly feeds on all species of animals within its range (Peterson and Ciucci 2003) except on humans, of whom it is usually afraid (Fritts et al. 2003; Karlsson et al. 2007; Mech 1970). The wolf's fear of humans, even though the animal is capable of killing them, must have resulted from selection acting on the wolves' enduring competition and negative interactions with humans (Shipman 2015). The animal has long had a reputation for being dangerous to humans, however, both in the Old and New Worlds, at least in part because it can carry rabies (Mech 1970; Mech and Boitani 2003; Young and Goldman 1944). Indigenous American peoples' fear of rabid wolves is well documented (Fritts et al. 2003; Lopez 1978; Young and Goldman 1944), although Pierotti and Fogg (2017) do not discuss this point. Even non-rabid wolves are capable of killing humans and in recent times non-rabid wolves have killed many children in India (Jhala and Sharma 1997; Rajpurohit 1999; Shahi 1983) and even a few adults in some areas (Butler et al. 2011; Linnell et al. 2002; McNay 2002). In at least some of these cases wolves have eaten the humans. Historically, wolves in most areas have been persecuted by humans (Fritts et al. 2003; Lopez 1978;
Mech 1970; Young and Goldman 1944). This duality that wolves were generally afraid of humans but sometimes attacked and ate them also pervaded into the period during the settlement of North America by Europeans (Lopez 1978; Young and Goldman 1944 and references therein).

Given this long-standing danger of wolves to hominids and the necessary animosity between the two, any proposal that a friendly relationship developed requires extraordinary evidence. The evidence summarized by Pierotti and Fogg (2017:34) is "...thirty years of research experience watching wolves and their interactions with humans and with one another..." combined with material collected by Pierotti (2011a, b) and by Fogg et al. (2015).

The 30 years of experience cited, however, involved not free-ranging (wild) wolves, but captive and pet wolves, wolf $\mathrm{x}$ dog hybrids (some of which were castrated), and dogs (Pierotti 2011a, b). Besides the obvious problem of extrapolating behavior of captive and pet wolves and dogs to wild wolves, two other issues arise about observing wolf $\mathrm{x}$ dog hybrids. One is that many claimed hybrids are really dogs sold fraudulently to obtain higher prices (Dogster 2014). The second is that claimed wolf $\mathrm{x}$ dog hybrids are often erroneously thought to contain higher amounts of wolf than they actually do. This is because breeders erroneously believe, for example, that backcrossing a $50 \%$ wolf and $50 \%$ dog with a $100 \%$ wolf yields a $75 \%$ wolf, and so on with further backcrossing. However, the actual amount of wolf in any individual hybrid can only be known in the F1 generation. Purported amounts of wolf in individual backcrosses are based on average amounts for populations rather than individuals. It is possible in any individual backcrossing that the $50 \%$ genes coming from the hybrid could be $100 \%$ dog in the backcross. In this respect, Pierotti and Fogg (2017:252) write of an $11 / 16$ hybrid without mentioning that such a claim cannot be validly made. Thus, observations of such animals or any other wolf $\mathrm{x}$ dog hybrid might only be reflecting the behavior of dogs. Nevertheless, Pierotti and Fogg (2017) spend much of their book discussing hybrids.

It is true that at least some wolves raised as pets can be friendly and endearing (Fentress 1967; Mech 1970; Pierotti and Fogg 2017). Especially endearing are wolf pups. However, pups hand-raised by humans must be obtained before four weeks old (Fentress 1967), preferably before three weeks old, for them to 
be tractable enough for humans to handle (Klinghammer and Goodman 1987; Kubinyi et al. 2007). Older wolves are impossible to tame (Woolpy and Ginsburg 1967). Wild wolves at three weeks old have just begun to come outside the den, and at four weeks old still spend much of their time in the den.

Occasionally an individual wild wolf will begin frequenting human campsites or dwellings, attracted by food, garbage, or dogs. In some of these cases, humans will then leave food for them and eventually begin throwing food to them. In one case, a wild wolf was attracted to dogs and people walking their dogs and became tamer and tamer (Jans 2015). Although the details are unknown, this wolf was also certainly fed as it became tamer.

When such wild wolves become conditioned to feeding from humans, they also habituate to them and seem friendly. However, in many cases, those wolves having lost their innate fear of humans are often the ones that attack people (Fritts et al. 2003; Linnell et al. 2002; McNay 2002). Neither Fogg et al. (2015) nor Pierotti and Fogg (2017) reported on these studies.

Considering the Fogg et al. (2015) stories, no explanation was offered as to why the relationships between indigenous Americans and wolves featured in them were exceptions to the way wolves and humans have interacted as enemies and competitors for millennia (Shipmen 2015), and for why these peoples were not afraid of the rabies wolves carried. Rabies was pervasive on every continent except Antarctica for all of recorded history (Hatami 2012), so hominids likely would have had a tradition of fearing, avoiding, and killing wolves for that reason alone. As discussed above, indigenous Americans were affected by rabid wolves and feared them because of it. Young and Goldman (1944:158) indicated that "the Indians were fully cognizant of the disease and greatly feared it." Lopez (1978:123) wrote about a Blackfeet man that "rabies was a real reason to fear wolves, for there were few more horrible deaths." According to Fritts et al. (2003: 291), "wolves were hunted and trapped by many Native American tribes, often with rituals and apologies to the spirit of wolves, but rarely with rancor or guilt."

\section{Reasons for Skepticism}

Thus, as a biologist who has studied wolf biology, behavior, interactions with humans, and conservation for 60 years, it is hard for me to understand how wolves could have been so unafraid and friendly toward humans and vice versa during the period and in the region covered by Fogg et al. (2015). Or were the animals named as wolves really dogs? Fogg et al. (2015) did indicate that some tribes considered the two animals as the same. If the accounts in question did involve dogs rather than wolves, then what value would the stories in question provide for inferences about how early humans interacted with wolves?

Only where a wolf population lived without exposure to hominids for centuries and then was gradually exposed to them, such as in North America's high Arctic during the past few centuries, could wolves perhaps lose their fear of humans. Even then or there, wolves would have remained competitors, potential prey, and rabies carriers when they did encounter humans.

Regarding the high Arctic, the vast region generally north of $75^{\circ}$ north latitude, few people inhabited the million $\mathrm{km}^{2}$ area for centuries, so most wolves in that area would never have seen a human. During the past several decades, when scientists and weather-station personnel visited or lived in a few scattered communities in this region, many had very close encounters with wolves (Mech 1988, 2017; Miller 1978, 1995; Munthe and Hutchinson 1978; Parmalee 1964). The wolves were curious but did not recognize humans as prey, behavior that attests that the species must have so consistently been harassed by humans that only those that did not recognize humans as prey survived. However, the more-or-less fearless behavior of this wolf population toward humans has not been documented at any other time or place. Everywhere else, evidence is strong that wolves and humans feared each other.

Other reasons to conclude that the stories related by Fogg et al. (2015) do not reflect reality is found by comparing the stories' details with what is known about basic wolf biology. For example, some of the accounts in Fogg et al. (2015) involve wolves teaching humans how to hunt. The methods that wolves use to hunt vary considerably depending on type of prey, habitat, and season, but most wolf hunts are failures and most successful hunts depend greatly on wolves running down their prey at speeds of up to $56 \mathrm{~km} / \mathrm{hr}$ (Mech 1970; Mech et al. 2015). Except for a few isolated cases of wolves possibly ambushing hares (Lepus arcticus) chased by packmates, there is little evidence that wolves employ particular strategies that might be useful to humans (Mech et al. 2015; Peterson and Ciucci 2003). 
Regarding cooperation with others that wolves allegedly taught the Tsitsistas of the Great Plains (Schlesier 1987:35, cited by Fogg et al. 2015), it is true that wolves hunt cooperatively. That cooperation, however, consists primarily of the whole pack chasing prey until they catch up, often single file. Then, especially with the largest prey, such as moose (Alces americanus) or bison (Bison bison), one wolf grabs the prey by the nose while the others tear at its rump. Even with smaller prey such as deer (Odocoileus spp.), multiple wolves attack at once (Mech et al. 2015). It is hard to understand what about this approach would be new or innovative to human hunters that wolves would be teaching them. It is true that in cases where wolves only wound prey, hominids perhaps could have finished them off sooner than the wolves. However, of the hundreds of observations of wolves hunting, only one resulted in wolves only wounding their prey and leaving, and that case involved one of the largest wolf prey, moose (Mech 1966).

Another friendly wolf behavior featured in some of the stories or historical accounts related by Fogg et al. (2015) is wolves taking care of humans in trouble. One such account based on Grinell (1926) and Hampton (1997, cited by Fogg et al. 2015:268) related to the Sand Creek Massacre in 1864 in the Colorado Territory:

... two Cheyenne women and their children escaped and took refuge in a cave under a bluff. After night fall, a male wolf entered the cave and lay down beside them. Afterwards, the wolf traveled with them, stopping to rest wherever they did, showing that its behavior was not simply coincidental. One woman addressed the wolf, telling it of their need for food, after which the wolf led them to a freshly-killed buffalo. For several weeks, the wolf remained, catching food and protecting them from potential human and nonhuman enemies.

Including the communication between the woman and the wolf, the behavior of this single wolf fits nothing we know about such wolves. If this animal were an individual pack member, it would have returned within a few days to its pack (Demma and Mech 2009). If it were a true lone wolf, it would have been traveling far and wide seeking a mate (Mech and Boitani 2003).

The above examples typify the numerous stories that Fogg et al. (2015) relate about indigenous
American peoples' interactions with wolves. From these narratives, the authors drew several conclusions. For example, Fogg et al. (2015:279) state that “... through much of the evolution of human hunting practices, wolves took the lead in initiating hunts." Knowing what we do about wolf hunting behavior from biological studies, humans following wolves on hunts would not have been very efficient because prey often detect wolves early and flee, and most wolf hunts are unsuccessful (Mech et al. 2015).

Fogg et al. (2015:278-279) also state that

Humans served as pupils in need of instruction, casting different light on the idea of how domestication may have proceeded, in that humans are at best partners, or students, of wolves and...the process of domestication in all human societies involved long running respectful relationships with free-living wolves.

The last statement is not documented, and the contention of respectful relationships itself during domestication has been challenged above. Further, the all-inclusive aspect of the statement, "in all human societies," would require considerable documentation, none of which was provided.

Pierotti and Fogg (2017) also concluded that wolves acted as sentinels, but it is unclear how they could have done so. Wolves do bark in alarm, but primarily in defending their dens or rendezvous sites (Harrington and Mech 1978). Lastly, the authors accepted Hyde's (1968) claim of villages guarded by hundreds of wolves, even though the largest wolf pack ever documented included 42 wolves, and such a large pack is extremely rare (Mech and Boitani 2003). Because wolf packs are basically territorial families that defend their territories lethally (Cassidy et al. 2015; Mech 1994; Mech and Boitani 2003), it would be highly unnatural for there to be an assemblage of hundreds.

Fogg et al. (2015:262) summarized the conclusions they reached from the stories they collected, arguing for “ “... a co-evolutionary reciprocal relationship between Homo sapiens and Canis lupus that existed from the early days of tribes until at least the nineteenth century." However, in view of the discrepancies pointed out above, these conclusions should be regarded as speculative at best, and the notion that American indigenous peoples' stories provide information about dog domestication must be viewed with much skepticism. 


\section{Conclusions}

Pierotti and Fogg's (2017) book is based primarily on the material presented by Fogg et al. (2015), as well as by Pierotti and Fogg's (2017) experience with nonwild wolves, wolf $\mathrm{x}$ dog hybrids, and dogs. However, this current article (1) presents arguments and evidence that question the value of such information for drawing conclusions about the relationship between early humans and wolves 14,000 yrs BP, (2) demonstrates how indigenous American stories contradict documented information about wolf biology, behavior, and interactions with humans, and (3) points out important information not considered by the authors about wolf attacks on humans and the importance of rabies in the wolf-human relationship.

Thus, it is difficult to accept Pierotti and Fogg's (2017:280) conclusion that "as long as humans considered themselves fellow predators of wolves, we lived comfortably with them," or that a "... coevolutionary relationship developed between two species that found one another compatible and was probably initiated by the wolves, to whom the humans eventually responded in a cooperative fashion" (Pierotti and Fogg 2017:3-4).

\section{Acknowledgments}

I thank Luc Janssens for suggestions to improve an early draft of this article, and to the anonymous reviewers who kindly provided valuable advice on the appropriate style for this article.

\section{Declarations}

Permissions: None declared.

Sources of funding: U.S. Geological Survey.

Conflicts of Interest: None declared.

\section{References Cited}

Araya, J. J., K. Kindscher, and B. N. Timmermann. 2012. Cytotoxic Cardiac Glycosides and Other Compounds from Asclepias syriaca. Journal of Natural Products. 75:400-407. DOI:10.1021/np2008076.

Butler, L., B. Dale, K. Beckmen, and S. Farley. 2011. Findings Related to the March 2010 Fatal Wolf Attack near Chignik Lake, Alaska. Wildlife Special Publication, ADF\&G/DWC/WSP-2011-2, Palmer, AK.

Cassidy, K. A., D. R. MacNulty, D. R. Stahler, D. W. Smith, and L. D. Mech. 2015. Group Composition Effects on Interpack Aggressive Interactions of Gray Wolves in Yellowstone National Park.
Behavioral Ecology 26:1352-1360. DOI:10.1093/ beheco/arv081.

Demma, D. J., and L. D. Mech. 2009. Wolf Use of Summer Territory in Northeastern Minnesota. Journal of Wildlife Management 72:380-384. DOI:10.2193/2008-114.

Dogster. Is It Responsible to Breed or Buy Wolf Dog Hybrids? 2014. Available at: https:// www.dogster.com/lifestyle/wolf-dog-breeds-

breeding-hybrid-dogs-rescue-adoption. Accessed on April 17, 2019.

Fentress, J. C. 1967. Observations on the Behavioral Development of a Hand-Reared Male Timber Wolf. American Zoologist 7:339-351.

Fritts, S. H., R. O. Stephenson, R. D. Hayes, and L. Boitani. 2003. Wolves and Humans. In Wolves: Behavior, Ecology, and Conservation, edited by L. D. Mech and L. Boitani, pp. 289-316. University of Chicago Press, Chicago.

Fogg, B. R., N. Howe, and R. Pierotti. 2015. Relationships Between Indigenous American Peoples and Wolves 1: Wolves as Teachers and Guides. Journal of Ethnobiology 35:262-285. DOI:10.2993/etbi-35-02-262-285.1.

Grinnell, G. B. 1926. By Cheyenne Campfires. University of Nebraska Press, Lincoln, NE.

Haber, G., and M. Hollerman. 2013. Among Wolves: Gordon Haber's Insights into Alaska's Most Misunderstood Animal. University of Alaska Press, Fairbanks, AK.

Hampton, B. 1997. The Great American Wolf. Henry Holt and Company, New York.

Harrington, F. H., and L. D. Mech. 1978. Wolf Vocalization. In Wolf and Man: Evolution in Parallel, edited by R. L. Hall and H. S. Sharp, pp. 109-132. Academic Press, New York.

Hatami, H. 2012. History of Rabies in Traditional Medicine's Resources and Iranian Research. Studies: On the Occasion of the World Rabies Day (September 28, 2012). International Journal of Preventive Medicine 3:593-595.

Hyde, G. E. 1968. A Life of George Bent, Written from His Letters. Edited by S. Lottinville. University of Oklahoma Press, Norman, OK.

Jans, N. 2015. A Wolf Called Romeo. Mariner Books, New York. 
Janssens, L., L. Giemsch, R. Schmitz, M. Street, S. Van Dongen, and P. Crombe. 2018. A New Look at an Old Dog: Bonn-Oberkassel Reconsidered. Journal of Archaeological Science 92:126-138. DOI:10.1016/j.jas.2018.01.004.

Janssens, L., A. Perri, P. Crombe, S. Van Dongen, and D. Lawler. 2019. An Evaluation of Classical Morphological and Morphometric Parameters Reported to Distinguish Wolves and Dogs. Journal of Archaeological Science: Reports 23:501-533. DOI:10.16/j.jasrep.2018.10.012.

Jhala, Y. V., and D. K. Sharma. 1997. Child-Lifting by Wolves in Eastern Uttar Pradesh, India. Journal of Wildlife Research 2:94-101.

Karlsson, J., M. Eriksson, and O. Liberg. 2007. At What Distance Do Wolves Move Away from an Approaching Human? Canadian Journal of Zoology 85:1193-1197. DOI:10.1139/Z07-099.

Klinghammer, E., and P. A. Goodmann. 1987. Socialization and Management of Wolves in Captivity. In Man and Wolf, edited by H. Frank, pp. 31-59. Dr. W. Junk Publishers, Boston.

Kubinyi, E., Z. Viranyi, and A. Miklosi. 2007. Comparative Social Cognition: From Wolf and Dog to Humans. Comparative Cognition and Behavior Reviews 2:26-46. DOI:10.3819/ccbr.2008.20002.

Linnell, J. D. C., R. Andersen, Z. Andersone, L. Balciauskas, J. C. Blanco, L. Boitani, S. Brainerd, U. Breitenmoser, I. Kojola, O. Liberg, J. Loe, H. Okarma, H. C. Pedersen, C. Promberger, H. Sand, E. J. Solberg, H. Valdmann, and P. Wabakken. 2002. The Fear of Wolves: A Review of Wolf Attacks on Humans. Norsk Institutt for Naturforskning, Trondheim, Norway. Available at: https:// mobil.wwf.de/fileadmin/fm-wwf/PublikationenPDF/2002.Review.wolf.attacks.pdf. Accessed on April 10, 2019.

Lopez, B. H. 1978. Of Wolves and Men. Charles Scribner's Sons, New York.

Marshall, J. 1995. On Behalf of the Wolf and the First Peoples. Red Crane Books, Santa Fe, NM.

McNay, M. E. 2002. A Case History of Wolf-human Encounters in Alaska and Canada. Wildlife Technical Bulletin 13. Alaska Department of Fish and Game. Available at: https://digitalcommons.unl.edu/cgi/ viewcontent.cgi? article $=1025 \&$ context $=$ wolfrecovery. Accessed on April 10, 2019.

Mech, L. D. 1966. Wolves of Isle Royale. National Parks Fauna Series No. 7. U.S. Government Printing Office, Washington, DC.

Mech, L. D. 1970. The Wolf: The Ecology and Behavior of an Endangered Species. Natural History Press, Doubleday Publishing Company, New York.

Mech, L. D. 1988. The Arctic Wolf: Living with the Pack. Voyageur Press, Stillwater, MN.

Mech, L. 1994. Buffer Zones of Territories of Gray Wolves as Regions of Intraspecific Strife. Journal of Mammalogy 75:199-202. DOI:10.2307/1382251.

Mech, L. D. 2017. Extinguishing a Learned Response in a Wild Wolf. Canadian Field Naturalist 131:2325. DOI:10.22621/cfn.v131i1.1951.

Mech, L. D., and L. Boitani. 2003. Wolf Social Ecology. In Wolves: Behavior, Ecology, and Conservation, edited by L. D. Mech and L. Boitani, pp. 1-34. University of Chicago Press, Chicago.

Mech, L. D., D. W. Smith, and D. R. MacNulty. 2015. Wolves on the Hunt: The Behavior of Wolves Hunting Wild Prey. University of Chicago Press, Chicago.

Miller, F. L. 1978. Interactions Between Men, Dogs, and Wolves on Western Queen Elizabeth Island, Northwest Territories, Canada. Musk-ox 22:70-72.

Miller, F. L. 1995. Status of Wolves in the Canadian Arctic Islands. In Ecology and Conservation of Wolves in a Changing World, edited by L. N. Carbyn, S. H. Fritts, and D. R. Seip, pp. 35-42. Canadian Circumpolar Institute, Edmonton, Canada.

Munthe, K., and J. H. Hutchinson. 1978. A WolfHuman Encounter on Ellesmere Island, Canada. Journal of Mammalogy 59:876-878. DOI:10.2307/1380164.

Parmelee, D. F. 1964. Myth of the Wolf. The Beaver Spring:4-9.

Peterson, R. O., and P. Ciucci. 2003. The Wolf as a Carnivore. In Wolves: Behavior, Ecology, and Conservation, edited by L. D. Mech and L. Boitani, pp. 104-130. University of Chicago Press, Chicago.

Pierotti, R. 2011a. Indigenous Knowledge, Ecology, and Evolutionary Biology. Routledge, New York. 
Pierotti, R. 2011b. The World According to Is'a: Combining Empiricism and Spiritual Understanding in Indigenous Ways of Knowing. In Ethnobiology, edited by E. N. Anderson, D. M. Pearsall, E. S. Hunn, and N. J. Turner, pp. 65-82. WileyBlackwell, Hoboken, NJ.

Pierotti, R. 2012. The Process of Domestication: Why Domestic Forms are Not Species. Wolfdog 2:22-27.

Pierotti, R., and B. R. Fogg. 2017. The First Domestication: How Wolves and Humans Coevolved. Yale University Press, New Haven, CT. DOI:10.2307/ j.ctt1wc7rbm.

Rajpurohit, K. S. 1999. Child Lifting: Wolves in Hazaribagh, India. Ambio 28:162-166. DOI: $10.2307 / 4314869$.

Schlesier, K. H. 1987. The Wolves of Heaven: Cheyenne Shamanism, Ceremonies, and Prehistoric Origins. Civilization of the American Indian Series, No. 183. University of Oklahoma Press, Norman, OK.

Shahi, S. P. 1983. Status of the Gray Wolf (Canis lupus pallipes, Sykes) in India. Acta Zoologica Fennica 174:283-286.

Shannon, L. M., R. H. Boyko, M. Castelhano, E. Corey, J. J. Hayward, C. McLean, M. E. White, M. A. Said, B. A. Anita, N. I. Bondjengo, J. Calero, A. Galov, M. Hedimbi, B. Imam, R. Khalap, D. Lally, A. Masta, K. C. Oliveira, L. Pérez, J. Randall, N. M. Tam, F. J. Trujillo-Cornejo, C. Valeriano, N. B. Sutter, R. J. Todhunter, C. D. Bustamante, and A. R. Boyko. 2015. Genetic Structure in Village Dogs Reveals a Central Asian Domestication Origin. Proceedings of the National Academy of Sciences 112:13639-13644. DOI:10.1073/pnas.1516215112.

Shipman, P. 2015. The Invaders: How Humans and Their Dogs Drove Neanderthals to Extinction. Harvard University Press, Cambridge, MA.

Smith, G. K. 1978. Slave to a Pack of Wolves. Adams Press, Chicago.
Thalmann, O., B. Shapiro, P. Cui, V. J. Schuenemann, S. K. Sawyer, D. L. Greenfield, M. B. Germonpre, M. V. Sablin, F. Lopez-Giraldez, X. DomingoRoura, H. Napierala, H.-P. Uerpmann, D. M. Loponte, A. A. Acosta, L. Giemsch, R. W. Schmitz, B. Worthington, J. E. Buikstra, A. Druzhkova, A. S. Graphodatsky, N. D. Ovodov, N. Wahlberg, A. H. Freedman, R. M. Schweizer, K.-P. Koepfli, J. A. Leonard, M. Meyer, J. Krause, S. Paabo, R. E. Green, and R. K. Wayne. 2013. Complete Mitochondrial Genomes of Ancient Canids Suggest a European origin of Domestic Dogs. Science 342:871-874. DOI:10.1126/science.1243650.

VonHoldt, B. M., J. P. Pollinger, K. E. Lohmueller, E. Han, H. G. Parker, P. Quignon, J. D. Degenhardt, A. R. Boyko, D. A. Earl, A. Auton, A. Reynolds, K. Bryc, A. Brisbin, J. C. Knowles, D. S. Mosher, T. C. Spady, A. Elkahloun, E. Geffen, M. Pilot, W. Jedrzejewski, C. Greco, E. Randi, D. Bannasch, A. Wilton, J. Shearman, M. Musiani, M. Cargill, P. G. Jones, Z. Qian, W. Huang, Z.-L. Ding, Y-p. Zhang, C. D. Bustamante, E. A. Ostrander, J. Novembre, and R. K. Wayne. 2010. Genome-wide SNP and Haplotype Analyses Reveal a Rich History Underlying Dog Domestication. Nature 464:898902. DOI:10.1038/nature08837.

Wang, G., W. Zhai, H. Yang, R. Fan, X. Cao, L. Zhong, L. Wang, F. Liu, H. Wu, L. Cheng, A. D. Poyarkov, N. A. Poyarkov, Jr., S. Tang, W. Zhao, Y. Gao, X. Lv, D. M. Irwin, P. Savolainen, C. Wu, and Y. Zhang. 2013. The Genomics of Selection in Dogs and the Parallel Evolution Between Dogs and Humans. Nature Communications 4:1860. DOI:10.1038/ncomms2814.

Woolpy, J. H., and B. E. Ginsburg. 1967. Wolf Socialization: A Study of Temperament in a Wild Social Species. American Zoologist 7:357-363.

Young, S. P., and E. A. Goldman. 1944. The Wolves of North America. American Wildlife Institute, Washington, DC. 